\title{
Anatomy-related ratios predict colonoscopy incompleteness in similar examination conditions
}

\author{
Sławomir Woźniak 1,A,C-F, Radosław Kempiński²,3,A-C,E,F, \\ Joanna Grzelak ${ }^{4, C, E, F}$, Zygmunt Domagała ${ }^{1, E, F}$, Friedrich Paulsen ${ }^{5, E, F}$ \\ ${ }^{1}$ Department of Human Morphology and Embryology, Division of Anatomy, Wroclaw Medical University, Poland \\ $22^{\text {nd }}$ Department and Clinic of Gastroenterology and Hepatology, Wroclaw Medical University, Poland \\ ${ }^{3}$ Medical Centre "Endomed", Wrocław, Poland \\ ${ }^{4}$ Department of Oral Anatomy, Wroclaw Medical University, Poland \\ ${ }^{5}$ Institute of Functional and Clinical Anatomy, Friedrich-Alexander University Erlangen-Nürnberg, Erlangen, Germany \\ A - research concept and design; B - collection and/or assembly of data; C - data analysis and interpretation; \\ $D$ - writing the article; $E$ - critical revision of the article; $F$ - final approval of the article
}

Address for correspondence

Sławomir Woźniak

E-mail: slawomir.wozniak@umed.wroc.pl

\section{Funding sources}

None declared

\section{Conflict of interest}

None declared

Received on November 27, 2019

Reviewed on January 19, 2020

Accepted on March 10, 2020

Published online on May 18, 2020

\section{Cite as}

Woźniak S, Kempiński R, Grzelak J, Domagała Z, Paulsen F. Anatomy-related ratios predict colonoscopy incompleteness in similar examination conditions. Adv Clin Exp Med. 2020;29(5):573-580. doi:10.17219/acem/118847

DOI

10.17219/acem/118847

\section{Copyright}

Copyright by Author(s)

This is an article distributed under the terms of the

Creative Commons Attribution 3.0 Unported (CC BY 3.0)

(https://creativecommons.org/licenses/by/3.0/)

\begin{abstract}
Background. Screening colonoscopy is one of the most popular modalities for screening and surveillance of colorectal cancer and other colon disorders.

Objectives. To introduce new ratios to predict the colonoscopy course in patients with similar characteristics.

Material and methods. Five hundred screening colonoscopies (252 females and 248 males) were performed by an experienced endoscopist. Incomplete colonoscopies (without pathologic findings, i.e., diseaseunrelated) were included in the study. Collected data was used to determine new ratios.

Results. An examination was completed in 231 (91.7\%) females (F) and 239 (96.4\%) males (M). The majority of incomplete colonoscopies were discontinued in the sigmoid colon: $8 \mathrm{~F}$ (38.1\%) and $4 \mathrm{M}(44.4 \%)$ or in the descendosigmoid flexure: $4 \mathrm{~F}(19 \%)$ and $2 \mathrm{M} \mathrm{(22.2 \% ).} \mathrm{We} \mathrm{found} \mathrm{statistically} \mathrm{significant} \mathrm{higher} \mathrm{risk}$ of incompleteness in females $(p=0.03)$, patients after 2 or more surgical treatments $(p=0.007)$ and in males with lower body mass index (BMI) $(p=0.01)\left(x^{2}\right.$ tests). Moreover, we discovered a statistically significant correlation with 2 or more previous surgical treatments in the female group $(p=0.02)\left(x^{2}\right.$ test). We calculated the incomplete colonoscopy anatomy-related (ICAR) and modified ICAR (MICAR) ratios. The range of ICAR and MICAR was $0-0.17$; the number of incomplete examinations ranged from 0 to 1 failed out of 6 attempts (calculation: 100:17 = 5.88).
\end{abstract}

Conclusions. The ICAR and MICAR ratios reflect the various risk of colonoscopy incompleteness (i.e., diseaseunrelated) and highlight the differences between patients in similar examination condition.

Key words: screening colonoscopy, incomplete colonoscopy, large intestine anatomy, colon anatomy-related incomplete colonoscopy 


\section{Introduction}

The rectosigmoid flexure, right colic flexure, left colic flexure, and the descendosigmoid flexure constitute sections with significantly limited mobility and can be regarded as critical points (CPs) for colonoscopy progress. Except for the primary flexures, specified above, which are always present, we also encounter secondary flexures (intratransverse in the transverse colon and/or intrasigmoid in the sigmoid colon). Some of the angulations are bent at a very sharp (acute) angle. That flexures are a key obstacle when performing colonoscopy in patients. ${ }^{1}$ The difficult colonic parts can be passed using special maneuvers, such as changing the patients' position or abdominal wall compression. The aim of these practices is to change the morphology of the colon segments and/or to correct looping of the endoscope. ${ }^{2}$ The endoscopist's skills in advancing the scope are a key factor for managing the difficulties. ${ }^{3}$ New scopes improvements, such as cuffs, caps and rings, are not always helpful. ${ }^{4}$

During $90 \%$ of all and $95 \%$ of screening colonoscopies (SCOs), the endoscope tip should be advanced into the cecum (with visualization the jejunocaecal valve). Such an examination is called a complete colonoscopy (CC). If the colonoscope advancing is stopped before reaching the cecum, the examination is classified as an incomplete colonoscopy (IC). In some patients, the reason for this lack of success remains unclear, although large intestine elongation and tortuosity are key causes. ${ }^{5-7}$ The attempts to pass through the problematic colonic segment are usually repeated several times during a single examination, but at some stage the decision to abandon attempts to negotiate the obstacle must be made. Some authors suggest that prolonged examination time (over $30 \mathrm{~min}$ ) and the inability to rotate the endoscope are the most important factors when making the decision to end the procedure. ${ }^{8}$

Screening colonoscopy is performed in patients without signs or symptoms suggesting colonic disease. During this procedure, the colonoscopist tends to diagnose the whole colon and if no pathology is found, the next routine SCO is scheduled within 10 years. ${ }^{9,10}$ The examination is usually performed in the left lateral decubitus position, because the supine position impedes conducting a colonoscopy by deepening the intestine tortuosity. ${ }^{11,12}$

According to some authors, in hysterectomized female patients, a colonoscopy is more difficult to conduct, ${ }^{13,14}$ although other studies do not confirm this statement. ${ }^{15}$ A further patient related factor is intra-abdominal fatty tissue (less tissue correlates with examination difficulties). ${ }^{16,17}$ The pain caused by peritoneal pulling and intestinal wall deformation is supposed to be one of the most frequent causes of ICs. ${ }^{18}$

We present some aspects that are not well known to specialists. The aim of this study was to introduce new ratios to predict the colonoscopy course. Moreover, we used these ratios to estimate the chances for $\mathrm{CC}$ in patients with a history of abdominal and/or pelvic surgery.

\section{Material and methods}

The patients participated spontaneously in the screening program sponsored by the Ministry of Health of the Republic of Poland. The eligible age range was 50-65 years (40-65 for patients with a history of a $1^{\text {st }}$ degree relative with colorectal cancer).

\section{Study design}

This is a six-month retrospective observational study (January to June, 2018), performed according to the Declaration of Helsinki and approved by the Bioethics Committee at Wroclaw Medical University (No. 689/2018). Five hundred asymptomatic subjects (approval 252 female (F) and 248 male $(\mathrm{M})$ ) undergoing SCOs were included. Patients' medical history was analyzed, including previous surgical treatments. The patients underwent mostly classical surgical treatment (ST), and in some cases laparoscopic surgery (LS) (transabdominal or transvaginal approach). Surgical treatment means open abdomen, while LS surgery is carried out with small incisions (with laparoscopic equipment). The patients underwent the following: appendectomy (34 F, 30 M; among them ST - 32 F, 29 M; LS - $2 \mathrm{~F}$ and $1 \mathrm{M}$ ), cholecystectomy (20 F, $8 \mathrm{M}$; ST - $18 \mathrm{~F}$, $7 \mathrm{M}$; LS - $2 \mathrm{~F}$ and $1 \mathrm{M}$ ), and cesarean sections (ST - 23). The other patients were treated because of uterine myomas (9 removals: ST $-8, \mathrm{LS}-1)$ and/or hysterectomy (10 F; ST -9 and LS -1 by abdominal approach), ovariectomy (ST - 9 F), linea alba, umbilical or inguinal herniotomy (ST -4 F). Very few patients underwent other surgical operations - $3 \mathrm{~F}$ - adnexectomy (ST), partial gastrectomy (ST) and retroperitoneal tumor removal (ST).

The examination was always started in the patient's left lateral decubitus position. No general anesthesia was applied. If the colonosope progress was stopped, the subject position was changed or their abdominal wall compressions (to dislocate the colonic segments) were performed.

\section{Colonoscopies}

Screening colonoscopies were performed in an outpatient clinic (Endomed, Wrocław, Poland) from Monday till Friday in the afternoon (between 3 p.m. and 7 p.m.). All the endoscopies were performed in similar examination conditions: the same sedation, scope and examiner. The examiner was an experienced specialist (over 10 years of endoscopy training; over 1,000 colonoscopies performed per year; cecum intubation rate over $95 \%$; adenoma detection rate in SCOs over 30\%; the skills of the gastroenterologist were certified by the Polish Society of Gastroenterology (Certificate of Advanced Skills in Colonoscopy)). Patients 
were prepared using a split regimen of 4 L of PEG (polyethylene glycol) solution with standard diet before. Sedation for the examination included oral administration of $7.5 \mathrm{mg}$ of midazolam 40 min before the procedure. Screening colonoscopies were performed with Pentax (Hoya Corporation, PENTAX Lifecare Division, Japan, Tokyo) endoscopes, series: EC-3890Fi2 (without stiffness control). Before the examination, written informed consent was obtained. Bowel preparation was evaluated with the Boston Bowel Preparation Scale. The preparation of the large bowel was either very good or good (8-9 or 6-7 points on the scale) in 419 $(89.15 \%)$ of the subjects; in the remaining patients it was sufficient. Polyps found during examination, measuring less than $10 \mathrm{~mm}$, were removed with an endoscopic snare (47 F, $68 \mathrm{M}$ ). In the case of larger polyps, a planned hospital polypectomy was scheduled (11 F, $19 \mathrm{M})$.

The location of the tip of the colonoscope was established using characteristic colon features and abdominal transillumination. The examinations were reported as CCs or ICs. Incomplete colonoscopies were divided into those where a pathological cause had been revealed (incomplete, pathological reasons colonoscopies - IPCs) and others (no reason for incompleteness, no pathology revealed, other than large intestine anatomy - IACs). The scope was then withdrawn during at least $6 \mathrm{~min}$. No perforation or other serious post-examination complications were observed.

\section{Grouping of the patients}

We grouped the patients according to gender, body mass index (BMI) and previous surgical treatments into clusters. The accumulated data was used to calculate ratios that "predict" the probability of performing ICs in patients with similar characteristics.

We performed calculations and created model curves of changing IAC risk in selected patients clusters, which can be used in subsequent examinations.

\section{Ratios}

Two ratios were calculated (described by Woźniak et al. ${ }^{19}$ ) according to the formulas: 1 . The IC a natomy-related ratio (ICAR) reflects the risk of incompleteness without showing the place of obstacle.

$$
\mathrm{ICAR}=\mathrm{IAC} \div \mathrm{CC}
$$

IAC - number of incomplete colonoscopies with no pathology revealed; $\mathrm{CC}$ - the number of complete procedures.

\section{Interpretation of the ICAR index}

The smaller its value, the lower the risk of the IAC. For example, hypothetically assuming: if 2 IACs occurred in a group of 100 examined persons, the calculated index value is 0.02 (quotient $=2$ divided by 100). This value means that next IAC is expected in 1 future case out of 50 patients.
2. The modified IC anatomy-related ratio (MICAR) reflects the decreasing risk of stopping in subsequent large intestine segments after advancing them with scope.

$$
\mathrm{MICAR} c p=\mathrm{IAC} c p \div \mathrm{CC}
$$

IAC $c p$ - the number of IAC which occurred before an analyzed colonic segment. It is calculated by subtracting the number of IACs at critical points passed with the colonoscope from the total number of IACs; $\mathrm{CC}$ - the number of complete procedures.

\section{Interpretation of the MICAR index}

The smaller the value, the lower the IAC risk. Hypothetical example: 100 examinations were performed in a homogenous cluster, out of which 6 were stopped at the left colic flexure and 7 at the right colic flexure (totally 13 IACs). As the scope approached the splenic flexure, the index value was 0.13 (quotient $=13$ divided by 100); when it passed this bending, the index dropped to 0.07 (quotient $=7$ divided by 100); after the right colic flexure, the value decreased to 0.0 (no failures after passing the RCF). The index value informs that in subsequent examinations, the discontinuation at the splenic flexure can happen in 1 out of 8 cases (MICAR 0.13; 100:13 = 7.69) and at the hepatic flexure 1 out of 15 cases (MICAR 0.07; $100: 7=14.28$ ); no stopping is expected after passing this critical point.

\section{Statistical analysis}

The statistical analysis was carried out using STATISTICA v. 12 software (StatSoft, Inc., Tulsa, USA). The $X^{2}$ test and Fisher's exact test were used for qualitative data analysis. The significance level for the study was $\mathrm{p}=0.05$. Based on the study calculations ( $\mathrm{p}=0.05$; test power goal 0.8 ), the minimal number of subjects to power the study was estimated at 102 for both genders (overall 204 patients are required). We decided to analyze a larger group consisting of 500 patients to provide homogenous conditions of the examinations (exclude the scope wear and tear).

\section{Results}

The results are shown in Fig. 1. Detailed subjects' characteristics are shown in Table 1 . In 4 male patients a neoplasm infiltration was found as a cause of incompleteness. Polyps were removed in 47 female (in 12 cases more than 1 ) and in 68 male patients (in 18 cases more than 1). Hospitalization was offered to 11 female and 19 male patients to address polyps bigger than $10 \mathrm{~mm}$ or the risk of complications (insufficient supervision after the procedure, suspected perforation or major bleeding after polypectomy).

In 26 IACs (21 F; $5 \mathrm{M}$ ) the colonoscopic progression was stopped before reaching the cecum. In the female group 


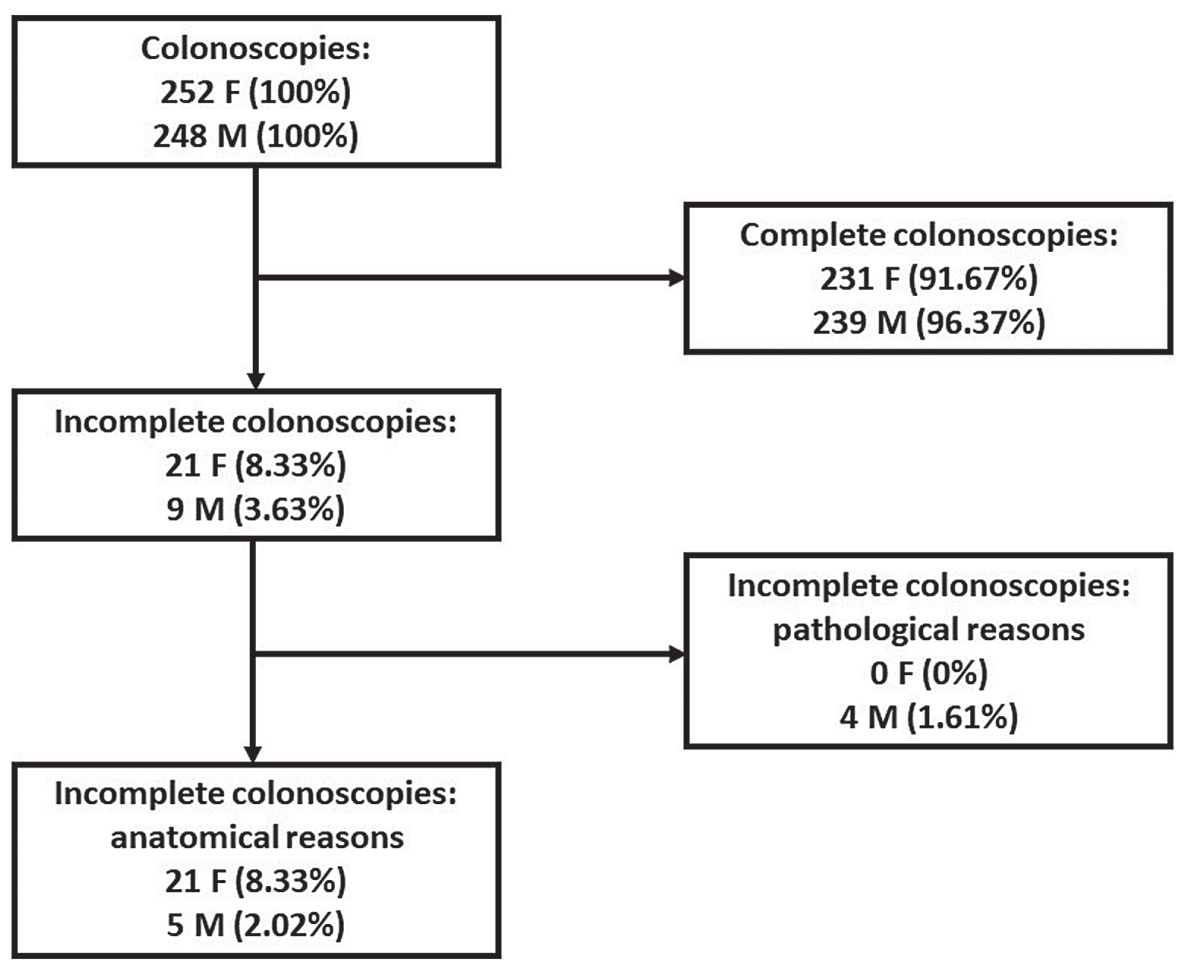

Fig. 1. Flowchart for study inclusion

Table 1. Characteristics of CCs and ICs subjects

\begin{tabular}{|c|c|c|c|c|c|c|c|}
\hline \multirow[b]{2}{*}{ Subject parameters } & \multicolumn{2}{|c|}{$\mathrm{CCs}$} & \multicolumn{2}{|c|}{$\mathrm{ICs}(\mathrm{IPCs}+\mathrm{IACs})$} & \multicolumn{3}{|c|}{$\mathrm{p}$-value (CCs vs ICs) } \\
\hline & $231 \mathrm{~F}$ & $239 \mathrm{M}$ & $21 \mathrm{~F}$ & $9 \mathrm{M}$ & $\begin{array}{l}\mathrm{F} \text { and } \mathrm{M} \\
\text { together }\end{array}$ & $\mathrm{F}$ & M \\
\hline $\begin{array}{l}\text { Age [years] } \\
\text { mean } \pm S D \text { ( } 40-65 \text { years) }\end{array}$ & $57.3 \pm 5.83$ & $56.9 \pm 6.01$ & $59 \pm 4.29$ & $57 \pm 5.93$ & 0.74 & 0.9 & 0.43 \\
\hline $\begin{array}{l}\text { Weight [kg] } \\
\text { mean } \pm S D(45-150 \mathrm{~kg})\end{array}$ & $70.0 \pm 12.5$ & $88.9 \pm 13.93$ & $70.1 \pm 13.75$ & $89.1 \pm 25.24^{*}$ & 0.15 & 0.76 & 0.05 \\
\hline $\begin{array}{l}\text { Height }[\mathrm{cm}] \\
\text { mean } \pm S D(150-200 \mathrm{~cm})\end{array}$ & $162.9 \pm 5.5$ & $176.6 \pm 7$ & $163.6 \pm 5.04$ & $175.9 \pm 7.47$ & 0.13 & 0.45 & 0.66 \\
\hline $\begin{array}{l}\mathrm{BMl} \\
\text { mean } \pm \mathrm{SD}\end{array}$ & $26.4 \pm 4.49$ & $28.4 \pm 4.01$ & $25.9 \pm 5.36$ & $27.9 \pm 7.13$ & 0.03 & 0.34 & $0.01^{* *}$ \\
\hline $\begin{array}{l}\text { After } 1 \text { PST } \\
\mathrm{n}(\%)\end{array}$ & $98(42.4)$ & $58(24.3)$ & $13(61.9)$ & $1(11.1)$ & 0.13 & 0.08 & 0.36 \\
\hline $\begin{array}{l}\text { After at least } 2 \text { PSTs } \\
n(\%)\end{array}$ & $24(10.4)$ & $8(3.35)$ & $4(19.05)$ & $0(0.0)$ & 0.007 & 0.02 & 0.82 \\
\hline $\begin{array}{l}\text { After at least } 1 \text { PST } \\
\text { in the pelvis }\end{array}$ & $33(14.3 \%)$ & 0 & $6(28.6 \%)$ & 0 & 0.064 & 0.37 & - \\
\hline
\end{tabular}

SD - standard deviation; CCs - complete colonoscopies; ICs - incomplete colonoscopies; IPCs - incomplete pathologic colonoscopies; IACs - incomplete "anatomy-related" colonoscopies; BMI - body mass index; PST - previous surgical treatment; F - female; M - male. Remarks: * 1 subject weight was 150 kg; ** the lower the BMI, the higher the risk of IC. Statistically significant differences are highlighted in bold.

with IACs: 8 colonoscopies were stopped at the sigmoid colon, 4 at the descendosigmoid flexure or splenic flexure, 3 at the descending colon, and 1 at the hepatic flexure or transverse colon. In the male group: 2 at the descendosigmoid flexure, 1 at the sigmoid colon, descending colon or transverse colon.

We found statistically important differences between colonoscopy completeness and BMI $(\mathrm{p}=0.03), 2$ or more previous surgical treatments $(\mathrm{p}=0.007)$ and female gender $(\mathrm{p}=0.03)\left(\mathrm{x}^{2}\right.$ test, respectively). Moreover, in the female group, a statistically significant positive correlation with more than 1 previous surgical treatment was found $\left(\mathrm{p}=0.02 ; \mathrm{X}^{2}\right.$ test), but no correlation with surgery in the pelvis. There were no statistically significant differences between the completion of the examination and the height or age of the patients. Collected data was used to determine new ratios: initial MICAR value reflects the ICAR value (which is constant in analyzed subjects). The detailed parameters for female group in relation to PSTs are shown in Table 2. 
Table 2. ICAR and MICAR values in female group in relation to previous surgical treatments

\begin{tabular}{|c|c|c|c|c|c|c|c|}
\hline \multirow[b]{2}{*}{ PSTs } & \multirow{2}{*}{$\begin{array}{c}\text { Number of IACs } \\
\text { and CCS }\end{array}$} & \multirow{2}{*}{$\begin{array}{l}\text { SCOs were } \\
\text { stopped at: }\end{array}$} & \multirow{2}{*}{$\begin{array}{l}\text { Number } \\
\text { of subjects }\end{array}$} & \multicolumn{4}{|c|}{ MICAR at subsequent critical points } \\
\hline & & & & $\begin{array}{c}\text { ICAR }=\text { MICAR } \\
(\mathrm{SC})\end{array}$ & $\begin{array}{l}\text { MICAR } \\
\text { (DSF) }\end{array}$ & $\begin{array}{l}\text { MICAR } \\
(\mathrm{LCF})\end{array}$ & $\begin{array}{l}\text { MICAR } \\
\text { (RCF) }\end{array}$ \\
\hline \multirow{4}{*}{0} & \multirow{2}{*}{$8 \mathrm{IACs}$} & SC & 3 & \multirow{4}{*}{0.06} & \multirow{4}{*}{0.04} & \multirow{4}{*}{0.01} & \multirow{4}{*}{0.0} \\
\hline & & DSF & 1 & & & & \\
\hline & \multirow{2}{*}{133 CCs } & DC & 3 & & & & \\
\hline & & LCF & 1 & & & & \\
\hline \multirow{4}{*}{1} & \multirow{2}{*}{$9 \mathrm{IACs}$} & SC & 4 & \multirow{4}{*}{0.12} & \multirow{4}{*}{0.07} & \multirow{4}{*}{0.05} & \multirow{4}{*}{0.0} \\
\hline & & DSF & 1 & & & & \\
\hline & \multirow{2}{*}{74 CCs } & LCF & 3 & & & & \\
\hline & & $\mathrm{TC}$ & 1 & & & & \\
\hline \multirow{3}{*}{ At least 2} & \multirow{2}{*}{$4 \mathrm{IACS}$} & SC & 1 & \multirow{3}{*}{0.17} & \multirow{3}{*}{0.125} & \multirow{3}{*}{0.04} & \multirow{3}{*}{0.04} \\
\hline & & DSF & 2 & & & & \\
\hline & $24 \mathrm{CCs}$ & RCF & 1 & & & & \\
\hline \multirow{4}{*}{$\begin{array}{l}\text { At least } 1 \text { PST } \\
\text { in lesser pelvis }\end{array}$} & \multirow{2}{*}{$7 \mathrm{IACS}$} & SC & 2 & \multirow{4}{*}{0.14} & \multirow{4}{*}{0.1} & \multirow{4}{*}{0.04} & \multirow{4}{*}{0.02} \\
\hline & & DSF & 3 & & & & \\
\hline & \multirow{2}{*}{$50 \mathrm{CCs}$} & $\mathrm{TC}$ & 1 & & & & \\
\hline & & RCF & 1 & & & & \\
\hline
\end{tabular}

PST - previous surgical treatment; IAC - incomplete anatomy-related colonoscopy; CC - complete colonoscopy; ICAR - incomplete anatomy-related colonoscopies ratio; MICAR - modified incomplete anatomy-related colonoscopies ratio; SC - sigmoid colon; DSF - descendosigmoid colon flexure; LCF - left colic flexure; TC - transverse colon; RCF - right colic flexure.

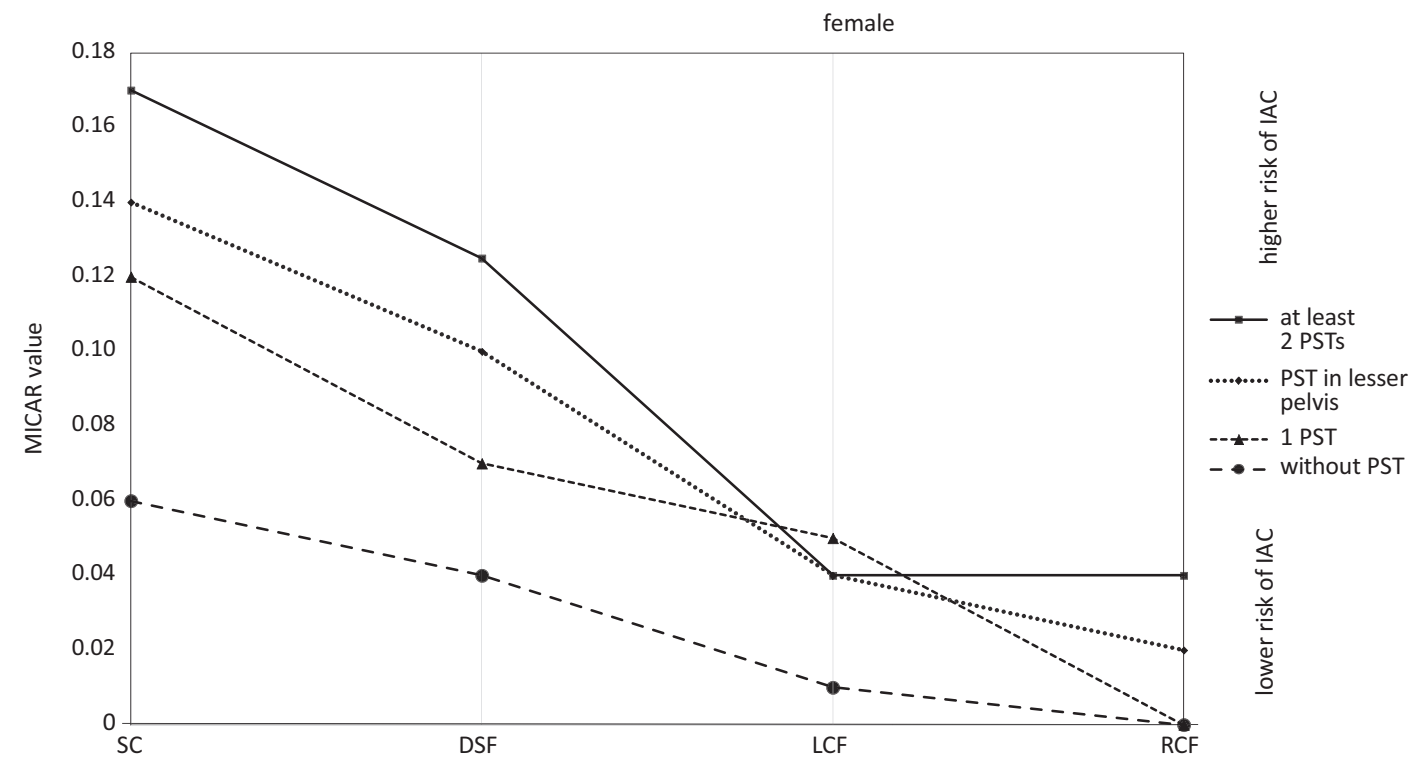

Fig. 2. MICAR in female patients with or without PSTS

SC - sigmoid colon; DSF - descendosigmoid flexure; LCF - left colic flexure; RCF - right colic flexure; IAC - incomplete anatomy-related colonoscopies: PST - previous surgery treatment.

In the cluster with at least 1 previous surgical treatment we defined a subgroup with at least 1 in the lesser pelvis (7 IACs and 50 CCs in this subgroup). Among the 7 IACs, 3 were stopped at the descendsigmoid flexure, 2 at the sigmoid colon, 1 at the transverse colon or right colic flexure, respectively; therefore, the ICAR was 0.14 . The respective values of the ratios in the particular female groups are shown in Fig. 2.

In the analyzed group with a BMI below 25 and with at least 2 previous surgical treatments, we had 4 IACs and $24 \mathrm{CCs}$ in the female subjects. In the subgroup of female subjects with a BMI of at least 25 without previous surgical treatment, we had 6 IACs and 115 CCs. Figure 3 shows the ratios curve in these strongly different female subjects.

\section{Discussion}

In our cohort, there were $8.3 \%$ incomplete examinations in female and $3.6 \%$ in male subjects. Some authors predict difficulties up to $10-20 \%$, others in $5 \%$ of SCOs. ${ }^{5,7,18,20}$ Our findings match these predictions. 


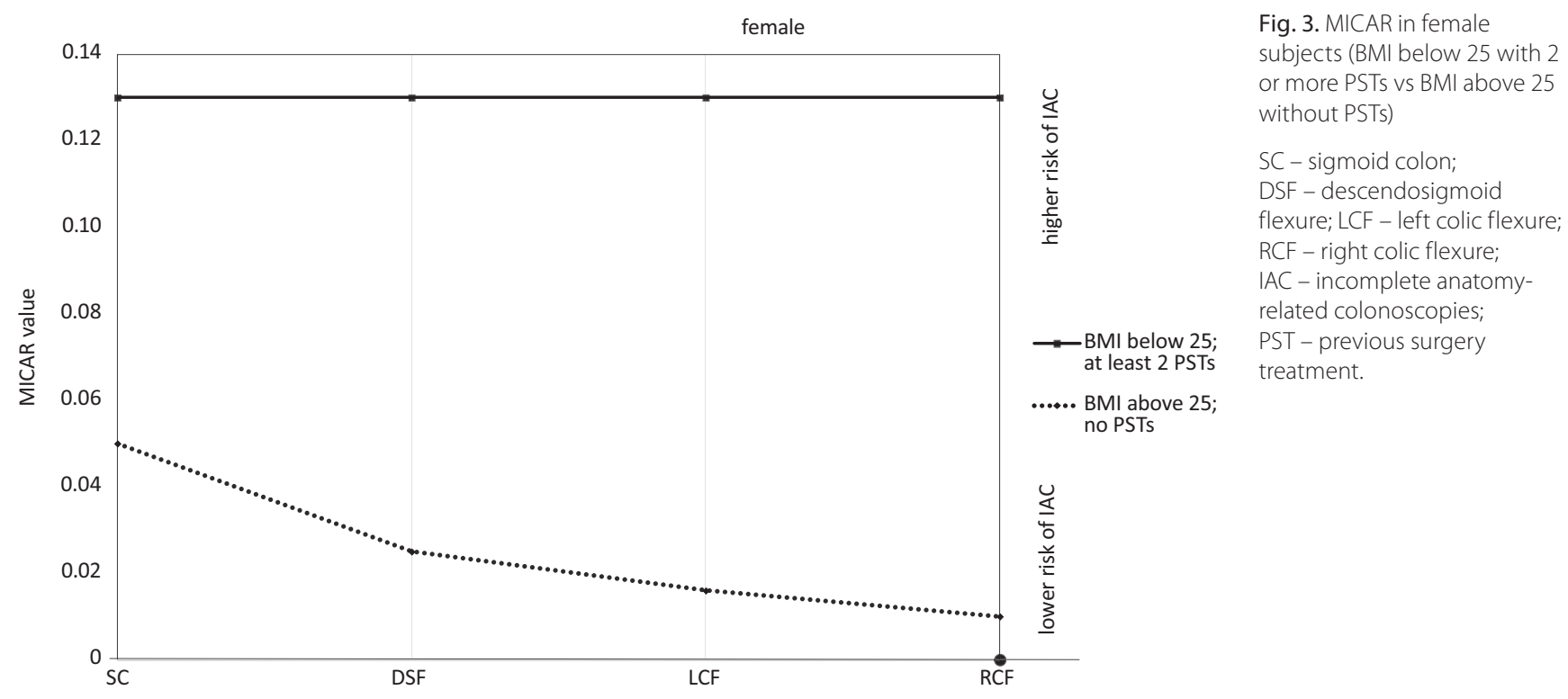

The advancing colonoscope encounters a series of acute flexures between contiguous colonic segments, either at the typical (the hepatic flexure, splenic flexure and descendosigmoid flexure) or at unexpected critical points - at the sigmoid or/and transverse colon. When the scope tip faces an acute flexure (defined as focal, $<90^{\circ}$ angle bend of the colon), its progression is stopped. The mean supposed number of acute flexures is $9.6 \pm 2.4^{5}$ and varies between patients. Rex et al. stated that the anatomical causes of difficulties in colonoscopy can be categorized into either an angulation and/or narrowing and/or redundancy of the colon. ${ }^{7}$ Pushing the instrument further will lead to the scope looping proximal to the obstacle or to the development of tension in the intestinal wall (and in the mesentery if the colon is suspended on it), frequently causing the patient pain. Special maneuvers used in such cases (changing the patient's position and/or applying pressure to the abdominal wall and/or scope rotation to reduce the loop) are not always effective. Therefore, flexures and mobility remain key factors in "predicting" the course of a colonoscopy.

These factors are unchangeable, while those related to the endoscopist and the scope used can be modified (another operator can perform the examination successfully and/or a different colonosocope can be advanced in the colon with less difficulty). In our study, the same professional performed the examination with the same series of scopes. To assure the constant conditions, we did not use the pediatric colonoscopies or $\mathrm{CO}_{2}$ or/and water immersion techniques. Using abdominal compression maneuvers did not allow us to overcome the colonic obstacle in the IAC patients. By providing such conditions, we exclude certain variables, such as the wear and tear of scopes and different examiners' skills. Consequently, the large intestine anatomy was analyzed without significant confounding factors. Based on the results, we established the ratios reflecting the risk of ICs in subsequent subjects grouped according to selected factors. In our opinion, this is the simplest and easiest way of showing the IAC risk to actual patients. Doctors routinely use descriptions of IC risk, such as odds ratio $(\mathrm{OR})$ or hazard ratio, but the terms are not easily understood and accepted by patients.

We propose the ICAR and MICAR ratios for "predicting" the risk of incompleteness in "similar" subsequent patients. The $1^{\text {st }}$ one reflecting the risk of general incompleteness without pointing at the specific point of stopping, while the $2^{\text {nd }}$ one reflecting the risk of incompleteness at specific colonic segment. At the beginning of the colonoscopy, ICAR is equal to MICAR, while on subsequent critical points MICAR drops gradually.

In our study the ICAR ranged between 0.17 and 0.06 , whereas MICAR ranged between 0.17 and 0.0 . The interpretation of the ratio values is extremely easy. For example, in females with at least 2 previous surgical treatments, these values inform at the beginning of the procedure that we expect every $6^{\text {th }}$ procedure (ICAR 0.17; calculation: $100: 17=5.88$ ) to be stopped before reaching the cecum. In a female without previous surgical treatment, we expect every $17^{\text {th }}$ examination (ICAR 0.06; 100:6 = 16.66) to be incomplete. Saunders et al. stated that it is important to explain to the patient why difficulties sometimes occur during intubation. ${ }^{21}$ We share the same opinion and propose an easy way to do so.

Rex et al. established that in lean women, a particularly sharp rectosigmoid angle is the reason for a more difficult colonoscopy course. ${ }^{7}$ Loeve et al. found the S-shaped sigmoid colon, U-shaped left colic flexure, the wide U-shaped transverse colon and the U-shaped hepatic flexure as the most challenging part to pass with the scope. ${ }^{18} \mathrm{We}$ found the sigmoid colon and the descendosigmoid (in female and male patients) flexure as the most difficult segments to pass on colonoscopy. Khashab et al. established the mean number of sharp-angle flexures as $10.9 \pm 2.4$ and pointed to the transverse colon as the main determinant in total 
large intestine length differences between patients. ${ }^{22}$ Philips et al., in contrast to the above statement, established that the rectosigmoid segment accounts for most of the variability in total colonic length. ${ }^{23}$ According to Shah et al., problems with colonoscope advancing are mainly expected to occur in the sigmoid colon and/or in transverse colon. ${ }^{2}$ We support the opinion that the sigmoid colon is the most problematic colonic segment.

Sadahiro et al. disclosed that older age is correlated with increased large intestine length and impaired intestine wall elasticity (in Japanese patients). ${ }^{24}$ Such changes can lead to loop formation and make the colonoscopy course more difficult. ${ }^{16,25}$ In our study, we have no statistically significant difficulties related to age; however, our subjects made up a specific group (40-65 years).

Some authors stated that performing a colonoscopy in females is more difficult. . $6,17,20,21,25$ This problem is related to the time needed to reach the cecum. Hsieh et al. and Krishnan et al. showed that in females this time is longer than in males. ${ }^{16,26}$ We support that conclusion, because in our study female colonoscopy was more often incomplete due to anatomical reasons.

It should be added that all the examinations were performed in the afternoon, so differences in the time of day could not influence our results. Interestingly, afternoon colonoscopies are supposed to have lower intubation rates. $^{27}$

The influence of previous surgical treatments on colonoscopy course is still unclear. Colonoscopy is more difficult to conduct in female patients who had previously undergone a hysterectomy, ${ }^{13,14}$ although some studies do not confirm this claim. ${ }^{15}$ Moreover, Garrett and Church established that posthysterectomy adhesions to the sigmoid colon make colonoscopy more difficult, but not in patients who were both hysterectomised and had their sigmoid colon resected. ${ }^{14}$ We do not support that claim. In our group, the key factor was the number of previous surgical treatments; it did not matter whether the operation took place in lesser pelvis or abdominal cavity.

We support the statement that a higher BMI is an important factor in predicting a fast and problem-free colonoscopy course. ${ }^{16,17,25,26}$ We observed a statistically significant incompleteness in males with a BMI below 25 .

\section{Limitations}

Our study has certain limitations. When the colonoscopy was stopped on a proximal critical point, we could not "predict" the course of the procedure on the next one. We could not totally exclude the individual sensitivity to pain - this factor can differ between patients. It is possible that the results would be different if other examination parameters (pediatric colonoscopies, water immersion or $\mathrm{CO}_{2}$ ) were employed during the procedure. And last, but not least, the endoscopist's fatigue was not measured.

\section{Conclusions}

The new ratios, ICAR and MICAR, are useful in "predicting" the colonoscopy course in the constant examination conditions. The curve derived from this indexes reflects a higher risk of large intestine anatomy-related colonoscopy incompleteness in patients, especially those with a history of 2 or more previous surgical treatments. There are no statistically significant differences between colonoscopy course and a history of 1 surgical operation (regardless whether conducted in the abdominal cavity or in the lesser pelvis)

\section{ORCID iDs}

Sławomir Woźniak (1) https://orcid.org/0000-0002-7450-7993 Radosław Kempiński (D) https://orcid.org/0000-0002-6030-2700 Joanna Grzelak (D) https://orcid.org/0000-0001-7957-1161 Zygmunt Domagała (D) https://orcid.org/0000-0002-2317-1932 Friedrich Paulsen (D) https://orcid.org/0000-0002-0527-0953

\section{References}

1. Wozniak S, Pytrus T, Kobierzycki C, Grabowski K, Paulsen F. The large intestine from fetal period to adulthood and its impact on the course of colonoscopy. Ann Anat. 2019;224:17-22.

2. Shah SG, Saunders BP, Brooker JC, Williams CB. Magnetic imaging of colonoscopy: An audit of looping, accuracy and ancillary maneuvers. Gastrointest Endosc. 2000;52(1):1-8.

3. Adler A, Wegscheider K, Lieberman D, et al. Factors determining the quality of screening colonoscopy: A prospective study on adenoma detection rates, from 12134 examinations (Berlin Colonoscopy Project 3, BECOP-3). Gut. 2013;62(2):236-241.

4. Jain D, Sandhu N, Singhal S. New developments in mechanical enhancement of colonoscopy: Cuffs, caps and rings. Digestion. 2016; 93(3):234-247.

5. Eickhoff A, Pickhardt PJ, Hartmann D, Riemann JF. Colon anatomy based on CT colonography and fluoroscopy: Impact on looping, straightening and ancillary manoeuvres in colonoscopy. Dig Liver Dis. 2010;42(4):291-296.

6. Hanson ME, Pickhardt PJ, Kim DH, Pfau PR. Anatomic factors predictive of incomplete colonoscopy based on findings at CT colonography. AJR Am J Roentgenol. 2007;189(4):774-779.

7. RexDK. Achieving cecal intubation in the very difficult colon. Gastrointest Endosc. 2008;67(6):938-944.

8. Gan T, Yang JL, Wu JC, Wang YP, Yang L. When and why a colonoscopist should discontinue colonoscopy by himself? World J Gastroenterol. 2015;21(25):7834-7841.

9. Brenner H, Chang-Claude J, Jansen L, Knebel P, Stock C, Hoffmeister M. Reduced risk of colorectal cancer up to 10 years after screening, surveillance, or diagnostic colonoscopy. Gastroenterology. 2014; 146(3):709-717.

10. Floer M, Meister T. Endoscopic improvement of the adenoma detection rate during colonoscopy: Where do we stand in 2015? Digestion. 2016;93(3):202-213.

11. Alazmani A, Hood A, Jayne D, Neville A, Culmer P. Quantitative assessment of colorectal morphology: Implications for robotic colonoscopy. Med Eng Phys. 2016;38(2):148-154.

12. Pickhardt PJ, Bakke J, Kuo J, et al. Volumetric analysis of colonic distention according to patient position at CT colonography: Diagnostic value of the right lateral decubitus series. AJR Am J Roentgenol. 2014;203(6):W623-W628.

13. Clancy C, Burke JP, Chang KH, Coffey JC. The effect of hysterectomy on colonoscopy completion: A systematic review and meta-analysis. Dis Colon Rectum. 2014;57(11):1317-1323.

14. Garrett KA, Church J. History of hysterectomy: A significant problem for colonoscopists that is not present in patients who have had sigmoid colectomy. Dis Colon Rectum. 2010;53(7):1055-1060.

15. Lacasse M, Dufresne $G$, Jolicoeur $E$, et al. Effect of hysterectomy on colonoscopy completion rate. Can J Gastroenterol. 2010;24(6):365-368. 
16. Hsieh YH, Kuo CS, Tseng KC, Lin HJ. Factors that predict cecal insertion time during sedated colonoscopy: The role of waist circumference. J Gastroenterol Hepatol. 2008;23(2):215-217.

17. Nagata N, Sakamoto K, Arai T, et al. Predictors for cecal insertion time: The impact of abdominal visceral fat measured by computed tomography. Dis Colon Rectum. 2014;57(10):1213-1219.

18. Loeve AJ, Fockens P, Breedveld P. Mechanical analysis of insertion problems and pain during colonoscopy: Why highly skill-dependent colonoscopy routines are necessary in the first place... and how they may be avoided. Can J Gastroenterol. 2013;27(5):293-302.

19. Wozniak S, Pytrus T, Woynarowski M, Pula B, Domagala Z, Iwanczak B. New colon anatomy-related ratios used to predict the course of colonosocopy in children. Adv Clin Exp Med. 2019;28(12):1-6.

20. Shah HA, Paszat LF, Saskin R, Stukel TA, Rabeneck L. Factors associated with incomplete colonoscopy: A population-based study. Gastroenterology. 2007;132(7):2297-2303.

21. Saunders BP, Fukumoto $M$, Halligan $S$, et al. Why is colonoscopy more difficult in women? Gastrointest Endosc. 1996;43(2 Pt 1):124-126.
22. Khashab MA, Pickhardt PJ, Kim DH, Rex DK. Colorectal anatomy in adults at computed tomography colonography: Normal distribution and the effect of age, sex, and body mass index. Endoscopy. 2009;41(8):674-678.

23. Phillips $M$, Patel A, Meredith P, Will O, Brassett C. Segmental colonic length and mobility. Ann R Coll Surg Engl. 2015;97(6):439-444.

24. Sadahiro S, Ohmura T, Yamada Y, Saito T, Taki Y. Analysis of length and surface area of each segment of the large intestine according to age, sex and physique. Surg Radiol Anat. 1992;14(3):251-257.

25. Chung GE, Lim SH, Yang SY, et al. Factors that determine prolonged cecal intubation time during colonoscopy: Impact of visceral adipose tissue. Scand J Gastroenterol. 2014;49(10):1261-1267.

26. Krishnan P, Sofi AA, Dempsey R, Alaradi O, Nawras A. Body mass index predicts cecal insertion time: The higher, the better. Dig Endosc. 2012; 24(6):439-442.

27. Sanaka MR, Shah N, Mullen KD, Ferguson DR, Thomas C, McCullough AJ. Afternoon colonoscopies have higher failure rates than morning colonoscopies. Am J Gastroenterol. 2006;101(12):2726-2730. 